\title{
Comments on Draft Compliance Program for Physicians.
}

\author{
From the Association of Pain Management Anesthesiologists. \\ (Now American Society of Interventional Pain Physicians)
}

The Association of Pain Management Anesthesiologists, (AOPMA), an association of pain management specialists dedicated to the pursuit of excellence in the education and practice of interventional pain management, submits these comments regarding the Draft OIG Compliance Program for Individual Physicians and Small Group Practices issued on June 12, 2000 by the Office of Inspector General (OIG), Department of Health and Human Services.

The AOPMA appreciates the significant efforts by the OIG in this guidance to acknowledge that smaller practices and individual physicians can only implement compliance programs that reflect their very limited resources. In this draft guidance, the OIG has endeavored to recognize that individual physicians and small group practices have very different resources, concerns, and needs than larger entities. We commend the OIG for building a significant measure of flexibility into this guidance, and strongly urge the OIG to ensure that such flexibility is retained in the final guidance. Although we were pleased to observe significant efforts towards making compliance programs manageable for small physician practices and for individual physicians, we believe that there are a number of serious deficiencies that need to be addressed by OIG in its final draft.

The AOPMA is itself committed to compliance. At great expense to itself and its members, AOPMA has developed a model compliance program that is designed to provide specific guidance to interventional pain management practitioners. We have attempted to identify and address every compliance risk area that can arise in this area of health care.

The above letter was sent to Honorable June Gibbs Brown, at the Office of Inspector General, during the comment period, in response to the draft OIG compliance program for individual physicians and small group practices.

\section{DEFINITIONOF A SMALLGROUP}

In its guidance, the OIG fails to provide any definition of what constitutes a "small group physician practice," despite the fact that many commentators to the original OIG Federal Register Notice on this issue stressed the tremendous importance of the critical definition. The OIG recommends that larger group practices, another undefined term, consult this guidance in conjunction with the previous guidance it issued for third-party medical billing entities. The OIG offers effectively no guidance as to the dividing line between a smaller group practice and a larger group practice. This deficiency leaves thousands of practitioners and practices without any indication as to whether they should look to the small practice model or that model and the third-party billing model.

Further, for those practices that should consider themselves to be "large practices," there is no guidance offered as to what elements of the third-party billing guidelines should be adopted. Large practices have expressed additional concern regarding OIG's statement that it is unwilling to develop a model for large practices. We do not believe that this decision is consistent with the OIG's obligation to provide meaningful guidance to providers of all types and kinds of providers.

Our members are very frustrated by the failure of OIG to address the basic point of who is and who is not a small physician practice. If the OIG is not able to provide a clear-cut method of determining whether the guidelines apply to a particular practice, the OIG should, at the very least, determine, the factors that should be considered in assessing this fundamental issue.

\section{APPROPRIATE FLEXIBILITY}

The AOPMA commends the OIG for its extensive acknowledgment that physician practices are not equivalent to large institutional providers of care and that full 
imposition of the standard seven elements may result in an unreasonable administrative burden. We believe the OIG is correct in noting that each physician practice must determine the level at which it will be able to implement each element. The specific level of implementation should depend on the size and resources of the practice, so long as each practice show a "good faith meaningful commitment to compliance" in each of these areas.

\section{COMPLIANCE OFFICER}

Recognizing the limitations on small practices, the OIG provided for some flexibility in the designation of a compliance officer as well. Consistent with our previous submission to the OIG in response to OIG's solicitation of input for its draft guidance, the OIG notes that the compliance officer could have other duties within the practice, or, in the alternative the duties of administering the program could be split and performed by more than one person acting as "compliance contacts." We strongly approve of this proposal.

The OIG goes on to approve of, and suggest, that another option would be to allow one person to serve as the compliance officer for more than one practice, enabling small practices to share resources. OIG also states that practices could also outsource the functions of the compliance officer. Although we laud the OIG's efforts to bless additional options for physician practices, there will be practical confidentiality concerns that must be addressed under any system where one individual serves as a compliance officer for multiple practices. We believe the OIG should, in the final guidance, more clearly alert practices that sharing a compliance officer with another practice may have significant confidentiality implications. One improvement might be for the OIG to caution practices that sharing of a compliance officer should only be undertaken after review of the arrangement by qualified counsel.

In this draft guidance, the OIG warned that if the compliance officer duties are outsourced, the compliance officer must still have sufficient interaction with the physician practice to effectively fulfill the required duties. There are practical difficulties with this suggestion. For example, there are limitations to having a compliance officer who spends most of his or her time off-site. On the other hand, the OIG warns that the compliance officer must be sufficiently independent to avoid potential conflicts of interest raised by the performance of the compliance officer's regular duties. The OIG, however, provides no specific guidelines on how to determine if a person is sufficiently "independent" or adequately "interactive" with the practice. We believe that these kinds of conflicting and hopelessly vague standards are a disservice to the provider community, leaving practitioners confused about a fundamental structural point that must be addressed in developing a compliance program.

\section{TRAINING AND EDUCATION}

In this draft guidance, the OIG states that new employees should be trained "immediately." In another sentence, however, the OIG states that training of new employees should take place within sixty days of their start date. This kind of internal inconsistency in the draft model has been the source of significant frustration for a number of our members who have reviewed the draft guidance to determine if their existing compliance programs would be considered adequate by the OIG.

In our view, sixty days is insufficient for a practice to provide compliance training. With no in-house "trainers" and the need to introduce many concepts and other issues to new employees before compliance training will, in many cases, even be meaningful, we urge the OIG to state that a ninety day limit should be seen as a "presumptive deadline," subject to additional time where reasonably required under the circumstances. We note that there are Corporate Integrity Agreements, signed by the OIG, that permit entities, even large entities, that have settled large federal fraud cases with more than sixty days to train new employees.

Even if OIG decides not to use a time standard that extends beyond sixty days, which we believe very strongly that it should, the OIG should, at an absolute minimum, clarify that sixty days is sufficiently prompt to be considered "immediate" training of a new employee.

Another point that we believe the OIG should clarify is the fact that, in the introduction, the OIG refers to the requirement of "comprehensive" training for all employees on the practice's policies and procedures. This suggests that all employees must be trained on all the details of the compliance program, regardless of their specific duties. At the same time, however, the OIG states that educational objectives for employees must be defined by each practice to identify who needs training, what form of training should be used, when training is needed, and how much training each employee should receive. 
This appears to be another instance where the draft guidance is contradictory. We believe the latter approach is preferable, as it would give practices and individual physicians maximum flexibility to utilize their possibly limited resources in an efficient manner. Does the OIG really believe that a part-time employee, who is a local high school student, charged only with running errands for the practice, needs to receive any training, let alone comprehensive training? We believe that the OIG has simply not considered the practical effect of some its rather categorical statements.

\section{SELF-REPORTING OF VIOLATIONS}

The draft guidance requires that practices address any violations within ninety days of the identification of the violation. The OIG's previous guidelines for other types of health care and related entities have required self-reporting within sixty days. Although we commend the OIG for recognizing that small physician practices may require a longer period of time to investigate potential violations, small practices, as a practical matter, will often require a longer time frame than merely ninety days in order to determine the proper person or persons to ask for guidance, perform fact-finding, and to establish whether a violation occurred.

Small practices do not typically even have existing health care attorney or consultant relationships. It may take a small practice ninety days or more just to find an expert to assist the practice in identifying whether or not there is a problem and what the appropriate course of action is.

The draft guidance and its time line seem to ignore the practical limitations our members and other health care providers across the country routinely experience in attempting to secure guidance from Medicare carriers and intermediaries, the Health Care Financing Administration, and state Medicaid agencies. One member recently reported that it took more than six months and more than five written inquiries for a Medicare carrier to finally concede that it could not answer the question that had been put to it. We note that advisory opinion requests to the OIG often take more than ninety days to secure.

In our previous submission, we recommended a response window of 180 days. We reiterate our strongly-held belief that this is the appropriate time frame for the OIG to adopt.

We also note that the OIG has left as ambiguous whether the recommended response window begins upon discovery of an actual violation or merely the point where a problem is suspected. We urge the OIG to clarify this point. With that said, we recommend very strongly that the OIG should calculate any short period for a response, such as ninety days, from the date that a practice actually determines that there is a problem.

\section{MISSTATEMENT OF CURRENT PROGRAM REQUIREMENT}

A number of commentators expressed concern earlier to the OIG about physician fears that the draft guidance would include statements that altered existing program requirements. The concerns focused on the danger that OIG would (1) exceed its regulatory authority, (2) usurp the authority of other agencies, and (3) not comply with the notice and comment provisions of the Administrative Procedures Act and the Medicare Carriers Manual. We fear that this concern was realized in the OIG's statement that the rationale for diagnostic or other ancillary services should be clearly identified if it will not be "easilyinferred" by a third-party reviewer.

In our view, this establishes a higher standard of documentation than is currently required, which require only that a rationale be "reasonably inferred" if not explicitly stated. Furthermore, the OIG's standard appears to not distinguish between the inferences made by clinicians and non-clinicians. If the OIG means to suggest that a nonclinician must be able to draw the required inference, this standard would create a remarkable burden on physician practices. It would, in fact, effectively require that every diagnostic or ancillary service have an explicit statement as to the rationale for the ordering of the service. This type of approach would find absolutely no support in the way that medicine is practiced in this country.

\section{ATTORNEY OPINIONS OF FINANCIAL RELATIONSHIPS}

In its draft guidance, the OIG states that physicians should have any proposed financial relationship involving a referral source reviewed by counsel. This sort of categorical statement ignores situations where such a standard would be unreasonable and unnecessary. It would constitute an incredible burden on physicians who, in all too many cases, are operating under the thinnest of margins. Some flexibility should be acknowledged, at a minimum, where the cost of attorney review is high relative to the 
value of the contract, where the relationship has been reviewed favorably by counsel for the other party to the proposed contract, where the physician has developed sufficient knowledge to evaluate the relationship, where the relationship is substantially the same as one that was provided a favorable review in an advisory opinion, and in other situations.

\section{PROFESSIONAL COURTESY GUIDANCE}

We very much appreciate the flexible and reasonable guidance that the OIG has supplied regarding professional courtesy, a source of tremendous confusion among our members for a long time. The implication of the OIG's discussion is that professional courtesy does not create a financial relationship within the meaning of the Stark Law to the extent that the restrictions on professional courtesy noted in the guidance are met. However, OIG does not address the Stark Law directly in its draft guidance. We urge OIG to specifically address this issue in its final draft.

\section{WRITTEN POLICIES AND PROCEDURES}

The draft guidance states that written policies and procedures are an essential component of an effective compliance program. We believe very strongly that this position is unreasonable and should be reevaluated by the OIG. Although we understand that written policies and procedures have their role and can be very important, there are circumstances in which they will add nothing to a small practice's compliance. Certainly, if a practice has drafted detailed standards of conduct, no additional benefit will be gained by adding policies and procedures. We are very concerned that practices that have developed reasonably detailed standards of conduct that address various specif- ics will be very discouraged by this component of the model, perhaps to the point of rethinking their ability to implement a compliance program.

\section{DOCUMENTING GUIDANCE REQUESTS AND THE GUIDANCE RECEIVED}

Although we agree that it is important to document these communications, we were very disturbed by what OIG did not state in this section. As a number of societies and other commentators have stated to the OIG, Medicare carriers, Medicare intermediaries, Medicaid agencies, and others with a responsibility to provide timely and accurate guidance to providers have utterly failed to meet this obligation. Although specifically asked to explicitly confirm the responsibility of these agencies, OIG has failed to do so. Moreover, OIG has not stated that it will not prosecute providers who have sought guidance, received it, and relied upon it. We believe that such a statement should be made as a simple matter of fairness.

\section{OIG MECHANISM TO ASSESS PLAN}

We also think the individual physician and small practice community (as well as the health care industry as a whole) would appreciate more formal insight and guidance from the OIG regarding specific compliance efforts. We suggest that the OIG devise a mechanism similar to the Stark Law and Anti-Kickback law advisory opinion process currently in place. For example, providers could submit their compliance programs or plans to the OIG, and the OIG could review the provider's submitted compliance programs or plans, and offer the provider the OIG's written assessment of the effectiveness of the plan. 